Research Article

\title{
Experimental Study on an Innovative Shear Connector in Steel-UHPC Composite Structure
}

\author{
Yang Liu $\mathbb{D}^{1,2}$ Dan Zeng $\left(\mathbb{D},{ }^{1}\right.$ Lei Cao $\mathbb{D D}^{2}$, and Naiwei Lu ${ }^{1}{ }^{1}$ \\ ${ }^{1}$ School of Civil Engineering, Changsha University of Science \& Technology, Changsha 410114, China \\ ${ }^{2}$ School of Civil Engineering, Hunan University of Technology, Zhuzhou 412007, China \\ Correspondence should be addressed to Dan Zeng; zengdan@stu.csust.edu.cn
}

Received 22 December 2020; Revised 12 April 2021; Accepted 16 April 2021; Published 28 April 2021

Academic Editor: Raffaele Landolfo

Copyright (c) 2021 Yang Liu et al. This is an open access article distributed under the Creative Commons Attribution License, which permits unrestricted use, distribution, and reproduction in any medium, provided the original work is properly cited.

In order to improve the stiffness and shear bearing capacity of steel-UHPC composite bridge, an innovative shear connector named arc-shaped reinforcement shear connector was proposed and compared with the stud and perforated bar steel plate shear connector using the static push-out test. Considering shear connector diameter, a total of ten push-out specimens for five groups were designed. The results indicated that the failure modes and failure mechanism of the arc-shaped reinforcement shear connectors were significantly different from stud shear connector and perforated bar steel plate. Obvious failure characteristics such as crack and reinforcement were not observed for the arc-shaped reinforcement specimens except for fine cracks on the top of one specimen, but these were observed for the others two types of shear connector. The relative slip value of arc-shaped reinforcement shear connector at the maximum load was the smallest and less than $1 \mathrm{~mm}$ in three types of shear connectors. The stiffness and shear bearing capacity of arc-shaped reinforcement were higher than those of stud and perforated bar steel plate under the same diameter. Increasing arc-shaped reinforcement diameter could improve significantly static behavior of shear connector. When the diameter of arc-shape reinforcement was increased from $8 \mathrm{~mm}$ to $12 \mathrm{~mm}$, the ductility factor, stiffness, and shear bearing capacity of arc-shaped reinforcement shear connector were improved by $174.32 \%, 214.76 \%$, and $54.2 \%$, respectively. A calculation method of shear bearing capacity was proposed by the least square method and multiple regression analysis and agreed well with the test result.

\section{Introduction}

Steel-concrete composite structure is the preferred structure for long-span bridge all over the world. With the rapid development of construction industry, lightweight construction products have gradually become the main structure of large-span bridges. Aiming at the technical problems of traditional bridge such as the limited spanning ability and poor durability [1], Shao et al. [2] took the superior performance of UHPC into composite structure and innovatively proposed the steelultra high performance concrete (UHPC) composite bridge, which effectively reduced the self-weight, the cracking risk in the negative moment zone, and the fatigue stress amplitude of the steel structure [3]. Shear connector is the key stress elements to ensure the steel beam and UHPC layer work together and to resist the horizontal shear force at the interface between steel beam and UHPC layer. In order to make full use of the mechanical advantages of materials, respectively, it is necessary to carry out deep research and discussion on the connection of composite structure.

At present, stud, channel steel, and PBL (perfobond rib) are commonly used as shear connector in the traditional steel-concrete composite structure, and extensive research had been conducted [4-6]. The research results demonstrated that different shear connectors exhibited their own advantages and disadvantages. The stud was easy for design and calculation owing to simple force mechanism. However, a large number of studs would lead to large amount of welding work. PBL shear connector showed good shear behavior, but it was difficult to be used in fabricated structure; meanwhile it consumes much steel and needs high cost. 
Since the performance of UHPC was greatly different from that of traditional concrete, and the thickness of UHPC layer of steel-concrete composite bridge deck was usually only about $50 \mathrm{~mm}$, the research results of shear connector embedded in steel-concrete composite structure could not be applied to steel-UHPC composite structure.

In recent years, some studies have been conducted to investigate the behavior of shear connector embedded in steel-UHPC composite structure. Cao et al. [7] studied the shear performance of short stud with the height-diameter ratio of 2.7 in steel-UHPC composite structure by push-out test, and it was found that studs were sheared off from the root of stud, while no appreciable damage was observed on the UHPC layer. Shao et al. $[8,9]$ investigated static behavior of the new local welded rebar mesh shear connector and the new shear connector of short rebar. The research results demonstrated that the shear bearing capacity of the short rebar shear connectors was slightly lower than that of the welded rebar mesh connectors. But the shear bearing capacity of them was higher than that of stud, and the relative slip value of them was lower than that of stud. These two novel shear connectors were used only in the ultrathin UHPC layer. Yan et al. [10] conducted the flexural experimental study of steel-UHPC composite beam with J-hook shear connector and proposed an analysis model of structural stiffness and strength of shear connector. This shear connector was complicated and was not convenient to construct. Wang [11] studied the static behavior of PBL shear connector embedded in steel-UHPC composite and found that there were high shear capacity and better ductility of PBL shear connectors. Shariati et al. $[12,13]$ proposed an innovative shear connector named C-shaped angle; the shear behavior was studied under the static and low cycle fatigue load. The research results show that $\mathrm{C}$-shaped angle shear connector could effectively improve the shear performance of the composite structure and has higher shear strength. Subsequently, the shear performance of rectangular steel pipe (RSP), tilted-shaped angle, and V-shaped angle was studied theoretically and experimentally by the research scholar such as Zhu et al. [14-17], respectively. Based on the finite element numerical analysis, the influence factors of shear strength and the calculation method of shear strength were analyzed.

From the above research results, stud shear connector embedded in the steel-UHPC was sheared off due to higher compression of UHPC and low shear capacity of stud. Other shear connectors such as PBL, C-shaped angle shear connector, and $\mathrm{V}$-shaped can provide higher bearing capacity, but it is inconvenient for them to construction and lots of steels will be consumed.

This paper proposed an innovative shear connector named arc-shaped reinforcement shear connector and investigated static behavior of arc-shaped reinforcement shear connector embedded in steel-UHPC composite structures compared to the stud and perforated bar steel plate shear connector through 10 push-out test specimens with the parameters of diameter. The failure mechanism and failure patterns were analyzed. The ultimate shear strength and relative interfacial slip of three types of shear connectors were measured. The regularity of load-slip curve, shear stiffness, ductility, and shear bearing capacity of three types of shear connector were analyzed and discussed. Furthermore, shear bearing capacity calculation method of arcshaped reinforcement shear connector was proposed.

\section{Experimental Study}

2.1. Push-Out Specimens Design. Referring to the push-out test method specified in Eurocode-4 [18], a total of 10 pushout specimens for 5 groups were designed and fabricated to investigate the effects of shear connector diameter. Figure 1 and Table 1 show the specific design parameters of the specimens. The arc-shaped reinforcement shear connectors were arranged in pairs along the $\mathrm{H}$-shaped steel in order to form a rectangular structure and were composed of three parts, the straight segment, the circular segment, and the straight segment. For the circular segment, it was designed as a semi-circular arc with a radius of $40 \mathrm{~mm}$. Figure 2 shows the design details. The $\mathrm{H}$-shaped steel with a sectional dimension of $200 \mathrm{~mm} \times 204 \mathrm{~mm} \times 12 \mathrm{~mm} \times 8 \mathrm{~mm}$ was used as the steel girder.

2.2. Push-Out Specimens Fabrication. H-shaped steel and three types of shear connector were fabricated and welded together using penetration welding for stud and double-face welding for steel bar and steel plate in factory, following a standard procedure, and then transformed to laboratory. Arc-shaped reinforcement adopted HRB400 ribbed rebar, and stud adopted ML15. All UHPC slabs were cast in laboratory. The length and diameter of steel fiber in UHPC are $13 \mathrm{~mm}$ and $0.16 \mathrm{~mm}$, respectively, and volume fraction is $1.5 \%$. Three groups of $100 \mathrm{~mm} \times 100 \mathrm{~mm} \times 100 \mathrm{~mm}$ cube specimens and $100 \mathrm{~mm} \times 100 \mathrm{~mm} \times 400 \mathrm{~mm}$ prism specimens were cast when pouring the UHPC slabs. Parameters of main material were obtained, as listed in Table 2. All pushout specimens were cured at room temperature for $48 \mathrm{~h}$ to final condensation and then steam-cured for $48 \mathrm{~h}$ continuously at the temperature from 90 to $100^{\circ} \mathrm{C}$. The flowchart of push-out specimens fabrication is shown in Figure 3.

2.3. Load and Test Methods. As shown in Figure 4, the pushout specimen was tested in an electrohydraulic servo pressure testing machine with a capacity of $500 \mathrm{t}$. A force spreading steel plate and a rubber sheet were placed between the loading plate and the top of the specimen to ensure a uniform load application. A dial indicator was installed at the bottom of the $\mathrm{H}$-type flange plate to measure the relative slip between the steel plate and the UHPC.

Test loading scheme: before testing, the specimen was loaded to $40 \mathrm{kN}$ to examine the proper functioning of the machine. During testing, the loading was first controlled by force and was loaded to $70 \%$ of the estimated maximum load at $40 \mathrm{kN}$ per stage. Then, loading was changed to displacement control and at a speed of $0.2 \mathrm{~mm} / \mathrm{min}$ until it dropped to $60 \%$ of the maximum load or the specimen was brought to failure. Load duration for each stage was 3-5 min, 


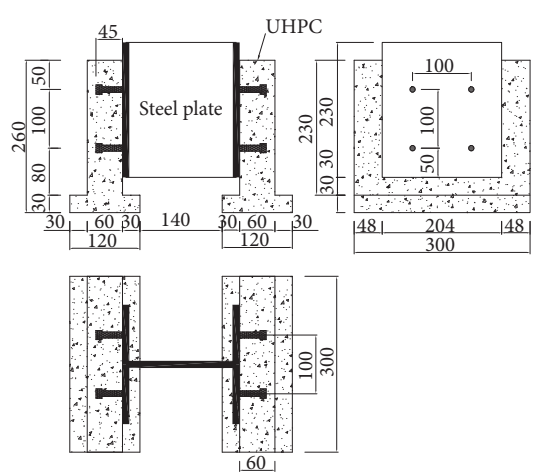

(a)

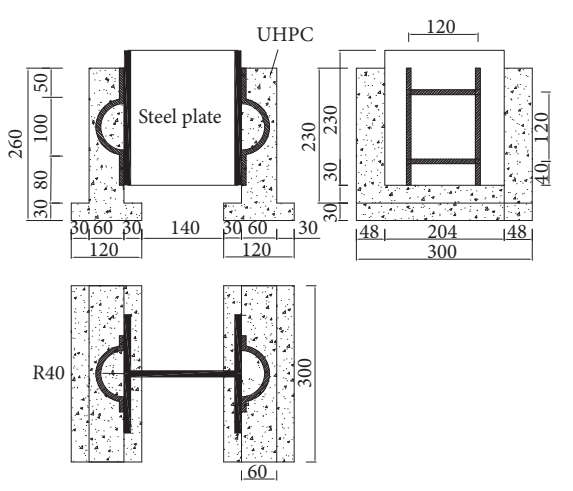

(b)
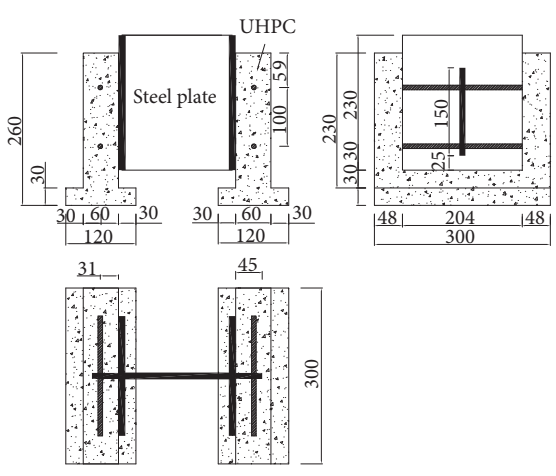

(c)

FiguRE 1: Design size of specimens. (a) Stud connector, (b) arc-shaped reinforcement connector, and (c) perforated bar steel plate connector.

TABLE 1: Specimen parameter design.

\begin{tabular}{|c|c|c|c|c|}
\hline $\begin{array}{l}\text { Types of shear } \\
\text { connectors }\end{array}$ & $\begin{array}{c}\text { Specimen } \\
\text { number }\end{array}$ & $\begin{array}{l}\text { The diameter of stud } \\
(\mathrm{mm})\end{array}$ & $\begin{array}{l}\text { The diameter of arc-shaped } \\
\text { reinforcement }(\mathrm{mm})\end{array}$ & $\begin{array}{l}\text { The diameter of perforated steel } \\
\text { bar }(\mathrm{mm})\end{array}$ \\
\hline \multirow[t]{2}{*}{ Stud } & $\begin{array}{l}\text { A-1-1 } \\
\text { A-1-2 }\end{array}$ & 10 & & \\
\hline & $\begin{array}{l}\text { C- } 1-1 \\
\text { C- }-1-2\end{array}$ & & 8 & \\
\hline \multirow[t]{2}{*}{$\begin{array}{l}\text { Arc-shaped } \\
\text { reinforcement }\end{array}$} & $\begin{array}{l}\text { C-2-1 } \\
\text { C-2-2 }\end{array}$ & & 10 & \\
\hline & $\begin{array}{l}\text { C-3-1 } \\
\text { C-3-2 }\end{array}$ & & 12 & \\
\hline $\begin{array}{l}\text { Perforated bar steel } \\
\text { plate }\end{array}$ & $\begin{array}{l}\text { B-3-1 } \\
\text { B-3-2 }\end{array}$ & & & 10 \\
\hline
\end{tabular}

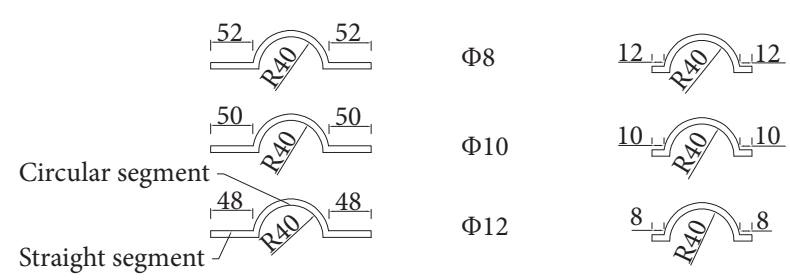

(a)

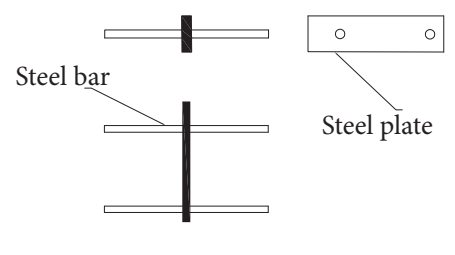

(b)

Figure 2: The design specification of shear connector. (a) The design specification arc-shaped reinforcements and (b) the design specification perforated bar steel plate.

TABLE 2: Parameters of main material.

\begin{tabular}{|c|c|c|c|c|c|}
\hline Parts & Material types & Elasticity modulus (MPa) & Yield strength $(\mathrm{MPa})$ & Tensile strength $(\mathrm{MPa})$ & Compressive strength (MPa) \\
\hline H-shaped steel & Q345 & $2.06 E 5$ & $3.45 E 2$ & $5.00 E 2$ & \\
\hline UHPC slab & UHPC & $4.26 E 4$ & & & $1.67 E 2$ \\
\hline Stud & ML15 & $2.06 E 5$ & $3.45 E 2$ & $4.00 E 2$ & \\
\hline Ribbed bar & HRB400 & $2.06 E 5$ & $4.00 E 2$ & $5.40 E 2$ & \\
\hline
\end{tabular}

and load value and relative slip value were recorded. Illustration of the test loading system is shown in Figure 4.

\section{Results and Discussion}

3.1. Push-Out Test Results. The test results of this study are shown in Table 3. Table 3 lists out maximum load, maximum relative slip, and ductility factor of three types of shear connectors. $P_{u}$ is the maximum load in the test process; $\delta_{u}$ is the relative slip value corresponding to the maximum load; $P_{\text {avg }}$ is the average load value; $\delta_{\text {avg }}$ is the relative slip value corresponding to the average load; $D_{c}$ is the ductility factor of the specimens; and $D_{\text {cavg }}$ is the average of $D_{c}$.

3.2. Analysis of Failure Pattern and Failure Mechanism. When the load reached 100 to $150 \mathrm{kN}$, bonding interface between $\mathrm{H}$-shaped steel and UHPC slab gradually separated 




FIgURE 3: Flowchart of push-out specimens fabrication.

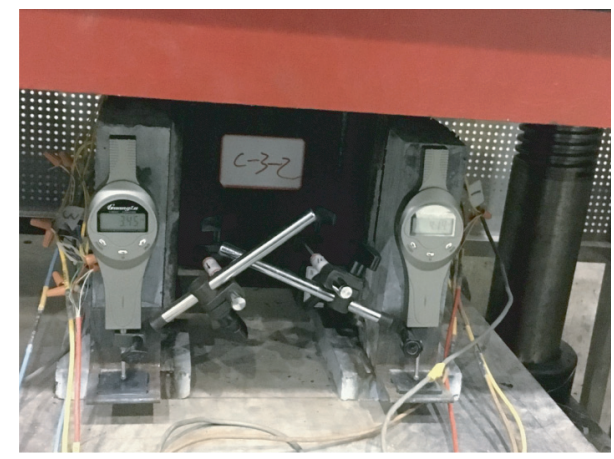

FIGURE 4: Illustration of the test loading system.

in the three groups of specimens, and the load at this stage was mainly undertaken by the friction between UHPC and $\mathrm{H}$-shaped steel. With the load increasing continuously, the failure modes of the three types of shear connectors were found to be quite different. Figures 5-7, respectively, show the failure modes of stud, perforated bar steel plate, and arcshaped reinforcement shear connectors.

Figure 5 demonstrates that the bearing capacity was undertaken by the studs after the occurrence of the interface separation between $\mathrm{H}$-shaped steel and UHPC slab. Moreover, the relative slip value and the gap width between $\mathrm{H}$-shaped steel and UHPC slab for group A specimens gradually increased, and the plastic deformation of the studs appeared. When the load reached its maximum value, the UHPC slab was completely separated from the $\mathrm{H}$-shaped steel and all the studs of group A specimen on one side were suddenly sheared off at the root of stud instead of the welding position. The local UHPC around the root of the studs was crushed without any visible concrete splitting on the surface of the UHPC slab. This phenomenon indicates that the UHPC can resist the crack propagation.

Figure 6 illustrates the failure mode of group B specimens. The sound of steel fiber tearing in UHPC could be heard in group B specimens during loading. The bearing capacity of the specimens was mainly undertaken by the rebar and UHPC. When the maximum load was reached, vertical cracks could be observed at the central part of bottom of UHPC slab and gradually widened and extended to the top. The bearing capacity was mainly undertaken by the rebar at the stage of bearing capacity decreasing, and finally the rebar fractured and lost bearing capacity.

Figure 7 demonstrates that when the load of group C decreased to $60 \%$ of the maximum load, except that there were some stress cracks on the top surface of the UHPC slab along the arc-shaped reinforcement for the C-3-2 specimen, the phenomena of arc-shaped reinforcement fracture and UHPC slab cracking were not observed on the other specimens. Test results indicated that the arc-shaped reinforcement shear connectors exhibited adequate toughness and bond force with UHPC. The arc-shaped reinforcement was welded on the $\mathrm{H}$-shaped steel and a closed-loop steel was formed; thus, the arc-shaped reinforcement gives better play to its tensile properties. Moreover, the UHPC in the closed loop can improve the shear resistance. Therefore, the arcshaped reinforcement shear connectors have relatively high shear capacity compared to the other shear connectors.

3.3. Analysis of Load-Slip Curve. Figure 8 exhibits the loadslip curves of three types of shear connectors. It can be seen from Figure 8 that the load-slip curves of push-out specimens of arc-shaped reinforcement and perforated bar steel plate show three obvious stages: the elastic stage, the elasticplastic stage, and the descending stage. When the load exceeded the maximum load, the specimens were sheared off suddenly, so the data cannot be collected in time and the descending stage of load-slip response of stud was not detected, and the load-slip curves of stud just show the first two stages; the results were consistent with Cao et al. [7] and Wang et al. [19]: (1) at the elastic stage, the load-slip curves 
Table 3: Push-out test results.

\begin{tabular}{|c|c|c|c|c|c|c|c|}
\hline \multirow{2}{*}{ Shear connector type } & \multirow{2}{*}{ Specimens } & \multicolumn{4}{|c|}{ Maximum } & \multicolumn{2}{|c|}{ Ductility factor } \\
\hline & & $P_{u}(\mathrm{kN})$ & $P_{\text {avg }}(\mathrm{kN})$ & $\delta_{u}(\mathrm{~mm})$ & $\delta_{\text {avg }}(\mathrm{mm})$ & $D_{c}$ & $D_{\text {cavg }}$ \\
\hline \multirow{2}{*}{ Stud } & A-1-1 & 430.65 & \multirow{2}{*}{446.06} & 1.27 & \multirow{2}{*}{1.31} & 2.25 & \multirow{2}{*}{2.51} \\
\hline & A-1-2 & 461.47 & & 1.36 & & 2.77 & \\
\hline \multirow{6}{*}{ Arc-shaped reinforcement } & C-1-1 & 1290.88 & \multirow{2}{*}{1168.11} & 0.56 & \multirow{2}{*}{0.61} & 2.04 & \multirow{2}{*}{2.18} \\
\hline & C-1-2 & 1045.33 & & 0.65 & & 2.32 & \\
\hline & C-2-1 & 1569.13 & \multirow{2}{*}{1475.46} & 0.61 & \multirow{2}{*}{0.64} & 3.29 & \multirow{2}{*}{3.29} \\
\hline & C-2-2 & 1381.78 & & 0.68 & & 3.29 & \\
\hline & C-3-1 & 1746.05 & \multirow{2}{*}{1801.26} & 0.96 & \multirow{2}{*}{0.86} & 6.19 & \multirow{2}{*}{5.98} \\
\hline & C-3-2 & 1856.47 & & 0.75 & & 5.77 & \\
\hline \multirow{2}{*}{ Perforated bar steel plate } & B-3-1 & 827.03 & \multirow{2}{*}{791.79} & 2.15 & \multirow{2}{*}{2.31} & 5.58 & \multirow{2}{*}{6.23} \\
\hline & B-3-2 & 755.35 & & 2.48 & & 6.88 & \\
\hline
\end{tabular}

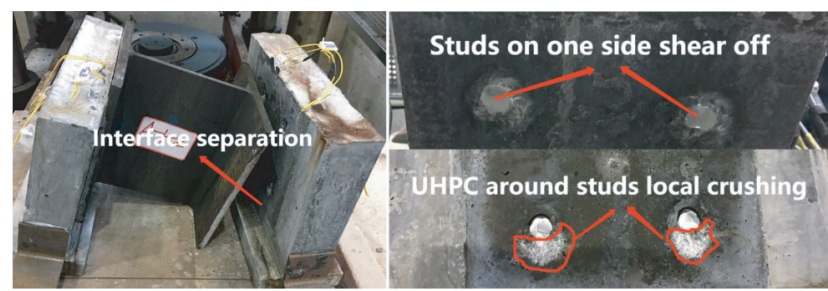

Figure 5: Failure modes of stud shear connector.
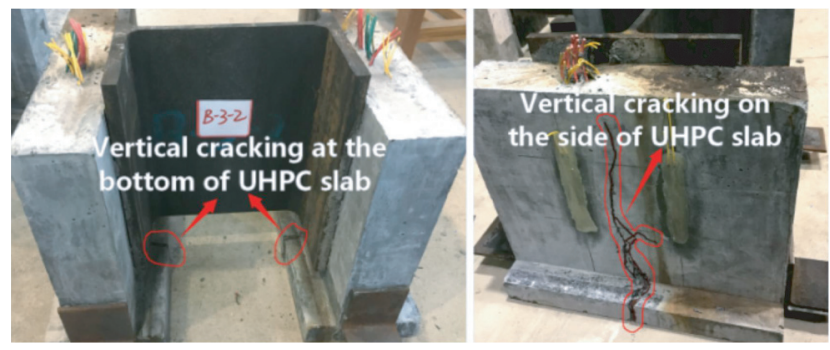

Figure 6: Failure modes of perforated bar steel plate shear connector.
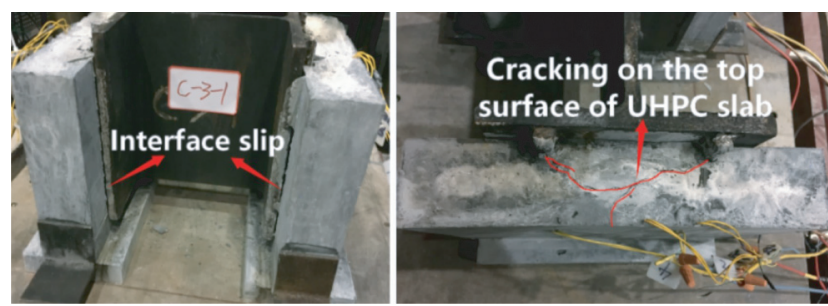

FiguRE 7: Failure modes of arc-shaped reinforcement.

exhibit approximately linear characteristic between load and relative slip value, which is indicated by the slope of the curve. The slope of specimens in group $\mathrm{C}$ is the maximum, and group B is next, while group A is the minimum. (2) At the elastic-plastic stage, when the load reaches $60 \%-70 \%$ of the maximum load, the relative slip at the interface between the UHPC and H-shaped steel plate increases rapidly with the vertical load increasing continuously. The slope of the curves decreases gradually, and the load-slip curves present nonlinear behavior. The slope of load-slip curves for the specimens in group A decreases rapidly, until it reaches the maximum load. However, the slope of load-slip curves for

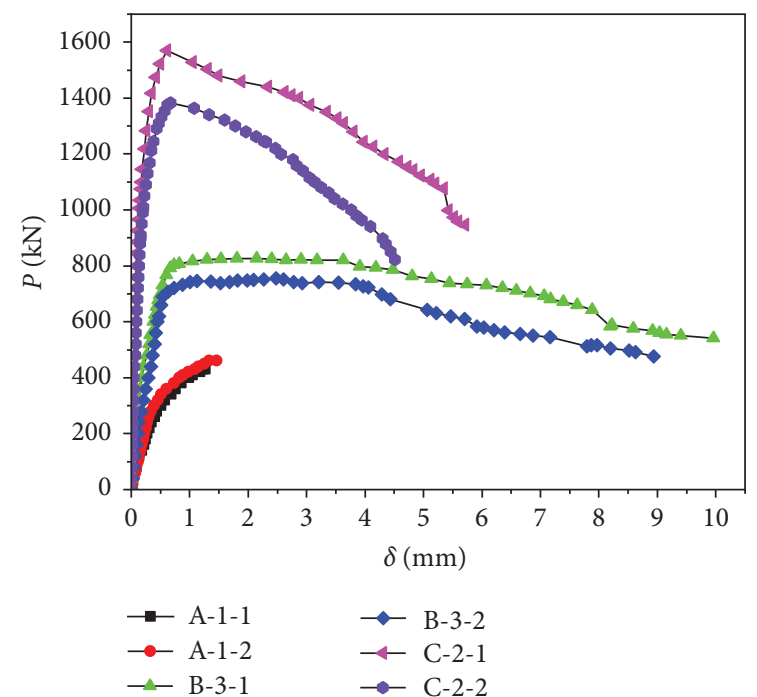

FIgURE 8: The load-slip curve of three shear connectors.

the specimens in group B decreases slowly in the early stage. When the bottom of the UHPC slab cracks, load-slip curves enter into platform stage and the slope of load-slip curves remains basically constant. The slope of load-slip for the specimens in group $\mathrm{C}$ decreases slowly all the time. Combined with the experimental statistical results presented in Table 3, it can be seen when the load reaches the maximum value, the relative slip value of specimens in group $C$ is the minimum; next is group $A$, and group $B$ is the maximum. It demonstrates that the arc-shaped reinforcement shear connectors exhibit the best ability to resist elastic-plastic deformation. (3) At the descending stage, the bearing capacity decreases continuously after the load reaches the maximum load and the relative slip increases rapidly. The descending curves of group B are relatively flat, while those of group $\mathrm{C}$ are relatively steep. When the load drops to about $60 \%$ of the maximum value, the relative slip of specimens in the group B and C specimens was about 9.45 and $5.61 \mathrm{~mm}$, respectively.

The load-slip curves of arc-shaped reinforcement with different diameters are plotted in Figure 9. The relative slips of arc-shaped reinforcement shear connectors are small at the rising stage and the relative slip corresponding to its maximum load is less than $1 \mathrm{~mm}$. The relative slip 


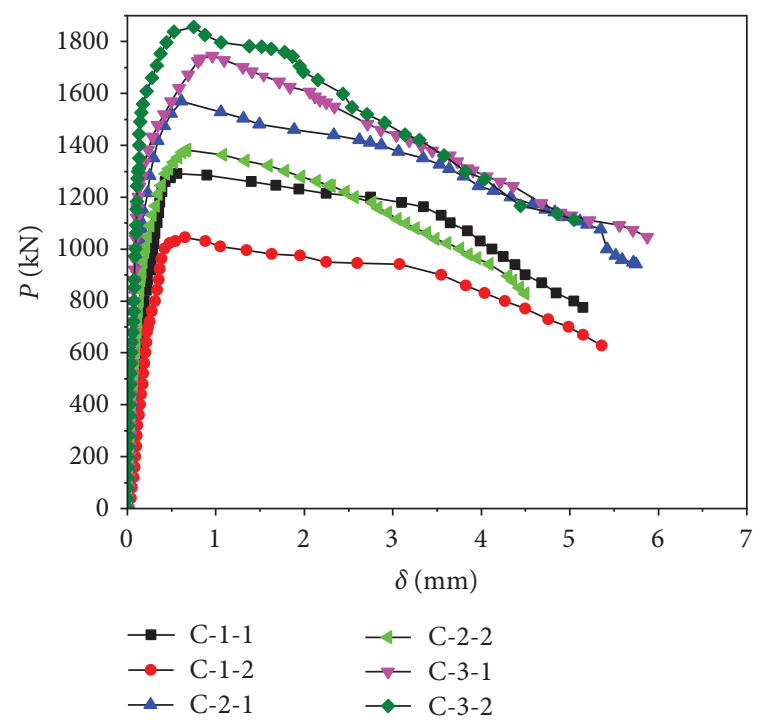

FIGURE 9: The load-slip curve of arc-shaped reinforcement.

corresponding to the maximum load increases with the diameter of arc-shaped reinforcement. Moreover, the slope of curve at the elastic stage becomes large with diameter of reinforcement increasing, which indicates that the diameter of reinforcement is an important factor affecting the shear stiffness of shear connectors.

3.4. Stiffness Analysis. The stiffness of shear connector reflects the ability to resist shear deformation, which is an important index to judge the deformation compatibility of composite structures [20]. Since the load-slip curve is nonlinear, the stiffness of each point on the curve was different; the discreteness and inaccuracy of the stiffness were large. At present, secant stiffness based on measured load-slip curve is usually used to calculate the shear stiffness of shear connectors, but there remains no unified shear stiffness calculation method. For example, the secant stiffness corresponding to $0.7 P_{u}$ was used to calculate the shear stiffness in Eurocode-4, while the Japan Steel Construction Association defined the secant stiffness at $1 / 3$ of the maximum shear capacity as the shear stiffness [21]. The load-slip curve of the specimen indicates that the slope of the curve is larger at the early service stage and decreases gradually at the later stage. As we all known, the proportional limit of loadslip curve is the characteristic point from linearity to nonlinearity. In this paper, the equation of the load-slip curve in the elastic phase could be firstly obtained by fitting the test results. Then, the intersection of fitting curve and the load-slip test curve was taken as the proportional limit point of load-slip curve. Finally, the proportional limit of specimens could be obtained as 0.66 by taking the average value of each specimen. In order to make the structure design safe and fully demonstrate the performance of shear connectors, the secant stiffness corresponding to the proportional limit of load-slip curve was defined as the shear stiffness of specimen in this paper; that is, the secant stiffness at $0.66 P_{u}$ was taken as shear stiffness of composite structure. By referring to the specification and relevant literature [18, 22], the shear stiffness of shear connectors was comparatively analyzed. The results are shown in Table 4.

Table 4 summarizes that stiffness calculation of the Japanese specification is closer to linear segment; thus, the results are larger. The stiffness calculation results of Eurocode 4 are more conservative, while the secant stiffness results corresponding to load proportional limit are moderate and can be better applied in structural design.

Figure 10 demonstrates that the shear stiffness of single arc-shaped reinforcement $\left(K_{s}\right)$ approximately increases linearly with the diameter of rebar $(d)$ increasing; its Pearson correlation coefficient is 0.974 . The shear stiffness of arcshaped reinforcement with a diameter of $12 \mathrm{~mm}$ and $10 \mathrm{~mm}$ is $214.76 \%$ and $88.46 \%$ higher than that of arc-shaped reinforcement with diameter of $8 \mathrm{~mm}$, respectively. Because increasing the diameter of the shear connector can improve the anchoring performance between shear connector and UHPC, the shear stiffness of arc-shaped reinforcement shear connector could be improved obviously with the increasing of the arc-shaped reinforcement diameter.

Figure 11 presents the comparative analysis results of the shear stiffness of arc-shaped reinforcement, studs, and perforated bar steel plate; it shows that the shear stiffness of arc-shaped reinforcement is significantly $815.66 \%$ and $294.44 \%$ larger than that of stud and perforated bar steel plate, respectively, with the same diameter. Since the bonding anchorage length between the arc-shaped reinforcement and UHPC slab is longer than that of studs and perforated bar steel plate, and the UHPC in the closed-loop which is formed by the arc-shaped reinforcement and $\mathrm{H}$-shaped steel plate plays the role of shear resistance, the shear stiffness of the arc-shaped reinforcement shear connector is obviously higher than that of other two shear connectors.

3.5. Ductility Analysis. Ductility is the ability of a component to exceed the elastic limit without brittle failure, which reflects the resistance to plastic deformation of the component. In order to measure ductility performance of components, ductility factor is usually used to reflect the post-elastic effect of components. At present, there is no uniform definition of ductility factor of shear connectors all over the world. Based on the relevant specifications and literature reports $[7,23,24]$, herein, the ductility factor is defined as a ratio of the limit slip to the design slip; that is,

$$
D_{c}=\frac{\delta_{u}}{\delta_{R d}},
$$

where $\delta_{u}$ is the relative slip value corresponding to ultimate bearing capacity $P_{u}$ and $\delta_{R d}$ is the relative slip value corresponding to the design load $P_{R d}$.

$$
P_{R d}=0.8 \frac{P_{u}}{\gamma},
$$

where $\gamma$ is the partial factor, and its value is 1.1 , and $P_{u}$ is the ultimate bearing capacity. The specific calculation results are presented in Table 3. 
TABLE 4: Comparison of three stiffness calculation methods.

\begin{tabular}{lccc}
\hline \multirow{2}{*}{ Specimens } & \multicolumn{3}{c}{ Calculation method and value of shear stiffness $\left(\mathrm{kN} \mathrm{mm}^{-1}\right)$} \\
& The Japan Steel Construction Association & Eurocode 4 & Proportional limit secant stiffness \\
\hline A-1-1 & 755.526 & 591.088 & 639.848 \\
A-1-2 & 866.604 & 680.056 & 761.816 \\
B-3-1 & 2506.162 & 1564.658 & 1675.614 \\
B-3-2 & 1798.452 & 1305.543 & 1578.204 \\
C-1-1 & 4577.599 & 3650.982 & 3835.917 \\
C-1-2 & 2701.119 & 2787.555 & 2974.073 \\
C-2-1 & 9257.422 & 6404.624 & 7235.301 \\
C-2-2 & 7676.572 & 5172.450 & 5599.133 \\
C-3-1 & 10878.816 & 9294.563 & 10151.348 \\
C-3-2 & 13027.839 & 10829.391 & 11283.905 \\
\hline
\end{tabular}

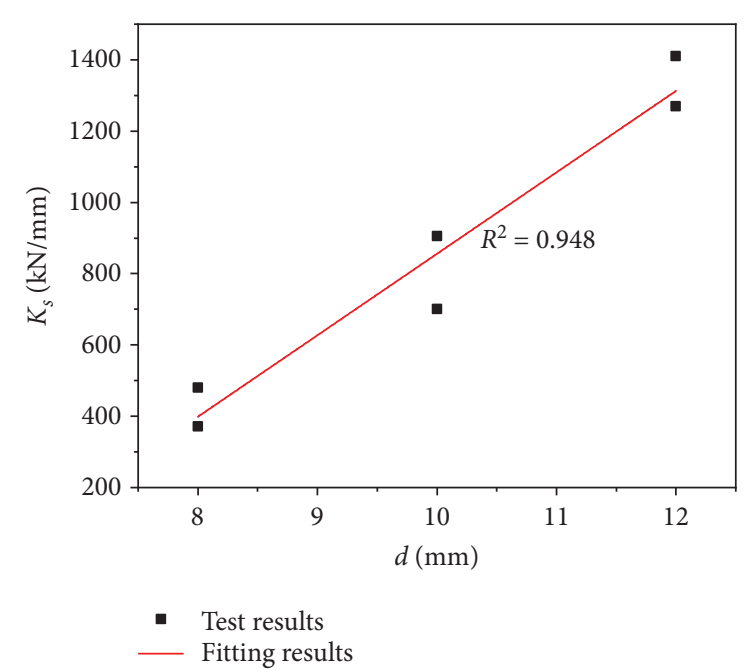

Figure 10: The relation curve between shear stiffness and diameter.

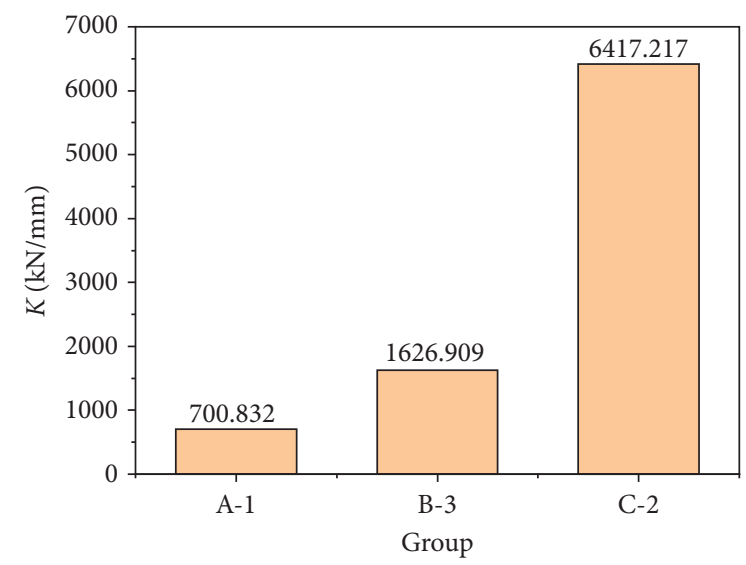

FIGURE 11: The shear stiffness comparison of three types of shear connectors.

The fitting curve of ductility factor $\left(D_{c}\right)$ and diameter $(d)$ was obtained by fitting the test data, which is shown in Figure 12. Its Pearson correlation coefficient is 0.968 , which indicates that the ductility coefficient shows a high correlation with the diameter of reinforcement. The ductility factor of shear connector increases linearly with diameter of

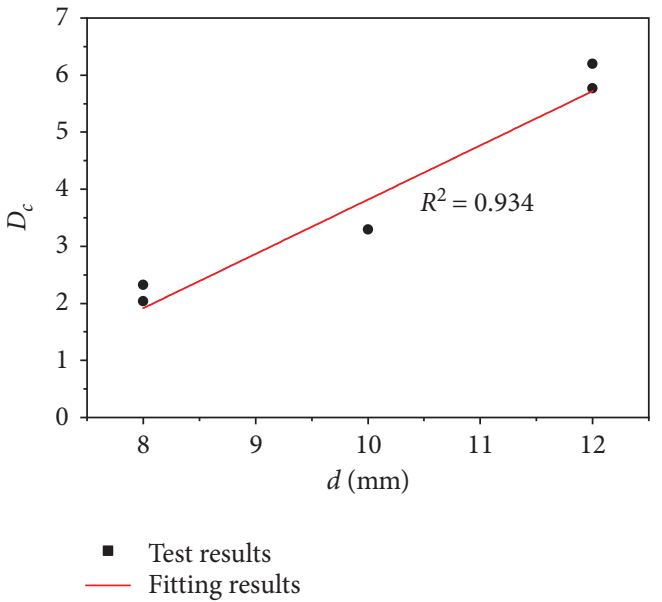

FIgURE 12: The relation curve between ductility factor and diameter.

arc-shaped reinforcement increasing, and the resistance to plastic deformation is also stronger. The ductility factors of arc-shaped reinforcement with a diameter of $10 \mathrm{~mm}$ and $12 \mathrm{~mm}$ are obviously $174.32 \%$ and $50.92 \%$ higher than arcshaped reinforcement diameter of $8 \mathrm{~mm}$, respectively. So increasing the diameter of arc-shaped reinforcement can improve the ductility of steel-UHPC composite structure bridge. Figure 13 shows the ductility factor of three types of shear connectors. It can be known from the figure that three types of shear connectors have good ductility. Under the same diameter, the ductility factor of perforated bar steel plate is best, next is arc-shaped reinforcement, and the stud is worst.

\subsection{Analysis of Shear Capacity}

3.6.1. Shear Bearing Capacity Comparison of Three Types of Shear Connectors. Table 3 presents the test results of shear capacity of studs, arc-shaped reinforcement, and perforated bar steel plate with the same diameter. The shear capacity of arc-shaped reinforcement is $230.78 \%$ and $86.49 \%$ higher than those of studs and perforated bar steel plate, respectively. Therefore, the arc-shaped reinforcement connector has higher shear capacity and can significantly improve the capacity of steel-UHPC composite structure. 


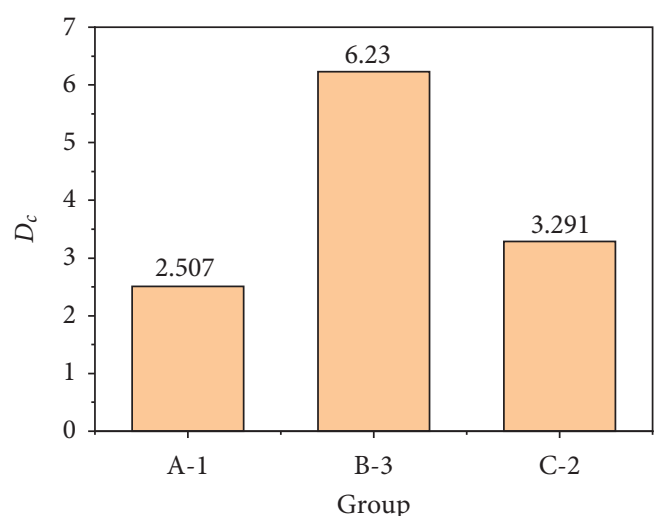

FIgURE 13: The ductility factor comparison of three types of shear connectors.

3.6.2. The Effect of Diameter on the Shear Capacity. Figure 14 illustrates that the shear bearing capacity of single arc-shaped reinforcement increases with the increase of reinforcement diameter. The maximum shear bearing capacity of the specimens with a diameter of $12 \mathrm{~mm}$ and $10 \mathrm{~mm}$ rebars increases by $54.2 \%$ and $26.3 \%$, respectively, compared to that of the specimens with a diameter of $8 \mathrm{~mm}$. The fitting curve obtained by fitting the experimental data revealed that the shear capacity of single arc-shaped reinforcement shows linear correlation with the reinforcement diameter, and its Pearson correlation coefficient is 0.939, which shows a good correlation between the shear capacity and reinforcement diameter.

3.6.3. Calculation Method of Shear Capacity. The arc-shaped reinforcement shear connector is an innovative shear connector which can be used in the steel-UHPC composite structure. Moreover, its mechanical behavior is also different from that of other shear connectors. At present, there is no applicable calculation method for shear capacity of the shear connector all over the world. According to the abovementioned experimental research and analysis, the shear capacity of arc-shaped reinforcement shear connectors is affected by the diameter of arc-shaped reinforcement, the arc area of the circular segment, the friction between UHPC and steel plate, and the strength of UHPC. The shear capacity is mainly undertaken by the arc-shaped reinforcement and the UHPC within the arc-shaped reinforcement.

The bearing capacity of arc-shaped reinforcement can be regarded as the bearing capacity of two combined bent rebars. The arc-shaped reinforcement is semi-circle shape, so the angle of bending rebar is 90 and the effect of angle of bending rebar can be ignored. In addition, the friction between UHPC and steel plate is very small compared to the shear capacity. In order to simplify the calculation, this paper ignored the bending rebar angle and the friction between UHPC and the steel plate. Referring to Germany and the former Soviet Union specification and according to the condition of rebar yielding [25], the formula of shear capacity of bending rebar is obtained as follows:

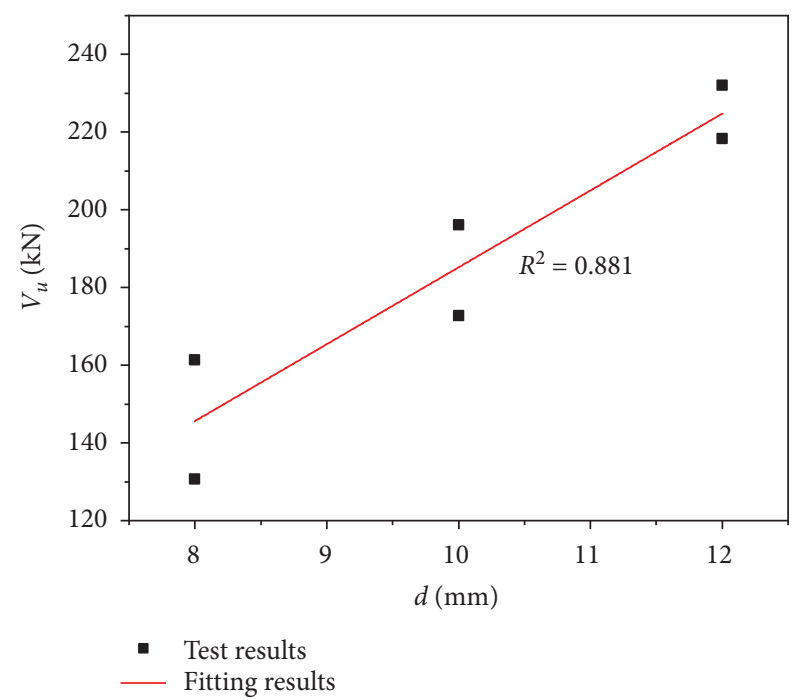

FIGURE 14: The relation curve between diameter and shear capacity.

$$
P_{R}=A_{s r} f_{y}
$$

where $A_{s r}$ is the area of bending rebar and $f_{y}$ is the yield strength of bending rebar.

Based on the research results on shear capacity of PBL shear connectors, the concrete shear block on the steel plate is an important part of the shear capacity for PBL shear connectors, and the concrete shear block area is linearly related to the shear capacity. The calculation formula of shear capacity of the concrete in steel plate holes can be obtained as follows [26]:

$$
Q=A_{s c} \sqrt{f_{c}}
$$

where $f_{c}$ is the compressive strength of concrete and $A_{s c}$ is the concrete area inside the arc-shaped reinforcement.

Based on the above mentioned analysis, the shear capacity of arc-shaped reinforcement shear connector can be composed of the arc-shaped reinforcement and UHPC shear block. Moreover, the friction between UHPC and steel plate is relatively small compared to its shear capacity. Therefore, the effect of friction can be ignored, and the shear capacity calculation formula of single arc-shaped reinforcement can be expressed as follows:

$$
V_{u}=\mu P_{R}+\beta Q=\mu A_{s r} f_{y}+\beta A_{s c} \sqrt{f_{c}},
$$

where $\mu$ and $\beta$ are the influence coefficients of arc-shaped reinforcement and UHPC shear block, respectively, on the shear bearing capacity, which can be obtained by regression according to the test results. The rest of the symbolic meaning is the same as mentioned above.

The least square method was used to fit the regression of the experimental data, and the influence coefficient $\mu=3.733$ and $\beta=2.601$ can be obtained. The correlation coefficient of fitting was 0.996 , which indicates that calculation results from the formula show a close fitting with the experimental results. Table 5 summarizes the calculation results and test results of the shear capacity of single arc- 
TABLE 5: The calculation results and test results of the shear capacity of single arc-shaped reinforcement shear connector.

\begin{tabular}{lccc}
\hline Specimens & $\begin{array}{c}\text { Test results } P_{t u} \\
(\mathrm{kN})\end{array}$ & $\begin{array}{c}\text { Calculation results } \\
(\mathrm{kN})\end{array}$ & $V_{u} / P_{t u}$ \\
\hline $\mathrm{C}-1-1$ & 161.360 & 147.350 & 0.913 \\
$\mathrm{C}-1-2$ & 130.667 & & 1.128 \\
$\mathrm{C}-2-1$ & 196.142 & 181.939 & 0.928 \\
$\mathrm{C}-2-2$ & 172.723 & & 1.053 \\
$\mathrm{C}-3-1$ & 218.256 & 226.329 & 1.037 \\
$\mathrm{C}-3-2$ & 232.058 & & 0.975 \\
\hline
\end{tabular}

shaped reinforcement. Table 5 presents that the ratio between the calculation results and the test results ranges from 0.913 to 1.128 with the average value of 1.006 and the coefficient of variation is 0.082 . Therefore, this formula can be used to calculate the shear capacity of arc-shaped reinforcement. It should be noted that the influence coefficients of arc-shaped reinforcement shear connector and UHPC shear block on the shear capacity are obtained by fitting the test data, and the contribution of them to the shear capacity remains indefinite, so the shear capacity calculation method of arc-shaped reinforcement shear connector needs further investigation and verification with more experimental data.

\section{Conclusion}

In this study, the shear performance of an innovative arcshaped reinforcement shear connector was analyzed compared to the two traditional shear connectors and the main research conclusions can be summarized as follows:

(1) Compared to the two traditional shear connector, the failure modes and failure mechanism of arc-shaped reinforcement shear connector specimens were found to be obviously different. After the arc-shaped reinforcement yielding, cracks and rebar fracture were not observed except for fine cracks on the top of the C-3-2 specimen; the arc-shaped reinforcement shear connectors have relatively higher shear capacity.

(2) By compassion of load-slip curves of three type of shear connectors, the slope of load-slip curves of the arc-shaped reinforcement was larger than the studs and perforated bar steel plate in both rising stage and descent stage. The relative slip value of the arcshaped reinforcement shear connector at the maximum load was the smallest in three types of shear connectors and less than $1 \mathrm{~mm}$ increases with the increasing of reinforcement diameter.

(3) A comparison of shear performance of three types of shear connector indicated that the ductility of perforated bar steel plate was the best, next was arcshaped reinforcement, and the stud was the worst, and the stiffness and shear bearing capacity of arcshaped reinforcement were higher than those of stud and perforated bar steel plate under the same diameter.
(4) The test program proved that increasing arc-shaped reinforcement diameter could improve significantly static behavior of shear connector, in terms of ductility factor, stiffness, and shear bearing capacity. The ductility factor, stiffness, and shear bearing capacity of arc-shaped reinforcement shear connector with a diameter of $12 \mathrm{~mm}$ were $174.32 \%$, $214.76 \%$, and $54.2 \%$ higher than those of arc-shaped reinforcement with a diameter of $8 \mathrm{~mm}$, respectively.

(5) Based on safety consideration, the calculation method of proportional limit secant stiffness was proposed. A calculation formula of shear bearing capacity was proposed by the least square method and multiple regression analysis and agreed well with the test result but needed to be further verified by more test data.

(6) The effect of the gap of arc-shaped reinforcement shear connector, the radius of arc-shaped reinforcement, and welding length on the shear behavior of arc-shaped reinforcement shear connector were not considered and need further research. In addition, numerical simulation and fatigue behavior of arc-shaped reinforcement shear connector deserve further research.

\section{Data Availability}

The data used to support the findings of this study are included within the article.

\section{Conflicts of Interest}

The authors declare no potential conflicts of interest with respect to the research, authorship, or publication of this article.

\section{Acknowledgments}

This research was financially supported by the Natural Science Foundation of Hunan Province (2019JJ50138), the Hunan Provincial Innovation Foundation for Postgraduate (CX20190637), the National Natural Science Foundation of China (NSFC) (51908068), and the General Project supported by the Education Department of Hunan Province (19C0566).

\section{References}

[1] S. Zhou and Z. H. Lou, "The status quo and developing trends of large-span prestressed concrete bridges with continuous rigid frame structure," China Journal of Highway and Transport, vol. 13, no. 1, pp. 31-37, 2000.

[2] X. Shao, L. Deng, and J. Cao, "Innovative steel-UHPC composite bridge girders for long-span bridges," Frontiers of Structural and Civil Engineering, vol. 13, no. 4, pp. 981-989, 2019.

[3] X. D. Shao, M. H. Qiu, B. F. Yan et al., "A review on the research and application of ultra-high performance concrete in bridge engineering around the world," Material Review (A), vol. 31, no. 23, pp. 36-46, 2017. 
[4] D. Lam and E. El-Lobody, "Behavior of headed stud shear connectors in composite beam," Journal of Structural Engineering, vol. 131, no. 1, pp. 96-107, 2005.

[5] S. Maleki and S. Bagheri, "Behavior of channel shear connectors, part I: experimental study," Journal of Constructional Steel Research, vol. 64, no. 12, pp. 1333-1340, 2008.

[6] Y. C. Yang and J. W. Cai, "Experiment on static behavior of perfobond shear connectors," China Journal of Highway and Transport, vol. 30, no. 3, pp. 225-263, 2017.

[7] J. H. Cao, X. D. Shao, L. Deng et al., "Static and fatigue behavior of short-headed studs embedded in a thin ultrahighperformance concrete layer," Journal of Bridge Engineering, vol. 22, no. 5, Article ID 04017005, 2017.

[8] X. D. Shao, Y. D. Gan, J. Li et al., "Interfacial shear resistance of welded structure of composite deck system composed of orthotropic deck and ultrathin UHPC layer," China Journal of Highway and Transport, vol. 31, no. 11, pp. 91-101, 2018.

[9] X. D. Shao, H. W. Zhang, J. Li et al., "Research on shear performance of short rebar connectors in steel- ultra thin UHPC lightweight composite deck," China Civil Engineering Journal, vol. 53, no. 1, pp. 39-51, 2020.

[10] J. Yan, H. Hu, and T. Wang, "Flexural behaviours of steelUHPC-steel sandwich beams with J-hook connectors," Journal of Constructional Steel Research, vol. 169, Article ID 106014, 2020.

[11] X. Wang, Researches on the Mechanical Behavior of PBL Shear Bond in Steel-UHPC Composite Structure, Nanjing Forestry University, Nanjing, China, 2018.

[12] M. Shariati, N. H. Ramli Sulong, M. Suhatril, A. Shariati, M. M. Arabnejad Khanouki, and H. Sinaei, "Behaviour of C-shaped angle shear connectors under monotonic and fully reversed cyclic loading: an experimental study," Materials \& Design, vol. 41, pp. 67-73, 2012.

[13] M. Shariati, A. Shariati, N. H. R. Sulong, M. Suhatril, and M. M. Arabnejad Khanouki, "Fatigue energy dissipation and failure analysis of angle shear connectors embedded in high strength concrete," Engineering Failure Analysis, vol. 41, pp. 124-134, 2014.

[14] X. Zhu, K. Takimoto, and H. Tanaka, "Analytical investigation of rectangular steel pipe shear connector," Structures, vol. 29, pp. 1404-1416, 2021.

[15] K. Khorramian, S. Maleki, M. Shariati et al., "Behavior of tilted angle shear connectors," PLoS One, vol. 10, no. 12, Article ID e0144288, 2015.

[16] M. Shariati, N. H. Ramli Sulong, A. Shariati, and M. A. Khanouki, "Behavior of V-shaped angle shear connectors: experimental and parametric study," Materials and Structures, vol. 49, no. 9, pp. 3909-3926, 2016.

[17] T. Farzad, M. Shervin, S. Mahdi et al., "Shear capacity of C-shaped and L-shaped angle shear connectors," PLoS One, vol. 11, Article ID e0156989, 2016.

[18] EN 1994-1-1 Eurocode 4, Design of Composite Steel and Concrete Structures, Part L-L: General Rules and Rules for Buildings, European Committee for Standardization, Brussels, Belgium, 2003.

[19] J. Q. Wang, J. N. Qi, T. Tong et al., "Static behavior of large stud shear connectors in steel-UHPC composite structures," Engineering Structures, vol. 178, no. 1, pp. 534-542, 2018.

[20] D. Lowe, R. Das, and C. Clifton, "Characterization of the splitting behavior of steel-concrete composite beams with shear stud connection," Procedia Materials Science, vol. 3, pp. 2174-2179, 2014.
[21] JSSC (Japan Society of Civil Engineers), Guidelines for Performance-Based Design of Steel-Concrete Hybrid Structures, JSSC (Japan Society of Civil Engineers), Tokyo, Japan, 2002.

[22] L. Xiao, Study of Static and Fatigue Behavior of PBL Shear Connectors in Steel-Concrete Composite Structure, Southwest Jiaotong University, Chengdu, China, 2012.

[23] BS EN 5400-2-2006, Steel, Concrete \& Composite Bridges, British Standards Institution, London, UK, 2006.

[24] S.-H. Kim, K.-T. Choi, S.-J. Park, S.-M. Park, and C.-Y. Jung, "Experimental shear resistance evaluation of Y-type perfobond rib shear connector," Journal of Constructional Steel Research, vol. 82, pp. 1-18, 2013.

[25] Z. Y. Zhang, Q. N. Li, and W. S. Jiang, "Shear capacity of flexural joints of steel-concrete composite beams," Sichuan Building Science, vol. 39, no. 3, pp. 4-7, 2013.

[26] J. H. Hu, M. X. Ye, and Q. Huang, "Experiment on bearing capacity of PBL shear connectors," China Journal of Highway and Transport, vol. 19, no. 6, pp. 65-72, 2006. 